03,13

\title{
Управление свойствами алмазоподобных кремнийуглеродных пленок
}

\author{
(C) А.И. Попов ${ }^{1,2}$, А.Д. Баринов ${ }^{1,2}$, В.М. Емец ${ }^{1}$, Т.С. Чуканова ${ }^{1}$, М.Л. Шупегин ${ }^{1}$ \\ ${ }^{1}$ Национальный исследовательский университет „МЭИ“, \\ Москва, Россия \\ ${ }^{2}$ Институт нанотехнологий микроэлектроники РАН, \\ Москва, Россия \\ E-mail: popovai2009@gmail.com
}

Поступила в Редакцию 28 мая 2020 г.

В окончательной редакции 28 мая 2020 г.

Принята к публикации 4 июня 2020 г.

Рассмотрены возможности управления электрофизическими и механическими свойствами аморфных алмазоподобных кремнийуглеродных пленок методами структурной, химической и структурно-химической модификации. В качестве факторов структурной модификации использовались величина напряжения смещения и его частота в процессе синтеза пленок, давление аргона в рабочей камере, а также прекурсоры с различной молекулярной структурой. Для химической и структурно-химической модификации осуществлялось введение в пленку переходных металлов с концентрацией до 30-35 at.\%. Показана высокая эффективность управления физическими свойствами пленок рассматриваемыми методами.

Ключевые слова: кремнийуглеродные пленки, полифенилметилсилоксан, полиметилсилоксан, структурная, химическая и структурно-химическая модификация, нанокомпозиты, электропроводность, нанотвердость.

DOI: $10.21883 /$ FTT.2020.10.49905.116

\section{1. Введение}

С материаловедческой точки зрения, успех в создании приборов и устройств во многом определяется возможностями управления свойствами исходного материала. Именно наличие метода контролируемого управления свойствами в микрообъемах кристаллических полупроводников путем легирования примесями замещения (донорными и акцепторными примесями) обеспечило современное развитие микро- и наноэлектроники.

Вместе с тем, сразу после открытия некристаллических полупроводников [1] была установлена слабая чувствительность этих материалов к примесям замещения, что явилось существенной преградой на пути их практического применения. Поэтому для управления свойствами некристаллических полупроводников был разработан ряд альтернативных методов. К ним относятся методы получения гидрогенизированного аморфного кремния, с низкой плотностью локализованных состояний [2], метод химической модификации свойств многокомпонентных халькогенидных стеклообразных полупроводников, заключающийся в введении значительного количества примеси (доли и единицы атомных процентов) при определенных условиях [3], метод структурной модификации свойств некристаллических полупроводников, основанный на изменении структуры материала при постоянном химическом составе $[4,5]$. В настоящей работе рассматриваются возможности применения методов химической и структурной модификации для управления свойствами относительно нового класса материалов - аморфных алмазоподобных кремнийуглеродных пленок.
Аморфные алмазоподобные кремнийуглеродные пленки, получаемые плазмохимическим разложением кремнийорганических соединений, обладают достоинствами алмазоподобных пленок аморфного углерода, но при этом свободны от многих недостатков последних [6], что открывает возможности их использования в качестве защитных и антифрикционных покрытий в различных областях техники [7-10]. В связи с этим разработка методов управления свойствами этих материалов представляет собой актуальную задачу.

\section{2. Изготовление образцов и методы исследования}

Схема установки для синтеза кремний углеродных пленок приведена на рис. 1 [11]. Кремнийорганический прекурсор подается в рабочую камеру через керамический диспергатор, расположенный на расстоянии 20-30 mm от вольфрамового термокатода (температура катода $\approx 2500^{\circ} \mathrm{C}$ ). Благодаря тепловому излучению катода, керамика разогревается до температуры $300-400^{\circ} \mathrm{C}$, что обеспечивает переход прекурсора в парообразное состояние. Разряд плазмы генерируется в перекрестных постоянном (радиальном) и переменном (аксиальном) полях. Магнетрон, расположенный в верхней части рисунка, служит для введения в растущую пленку металлов (см. раздел „Химическая модификация свойств“"), а натекатель 2 - для введения в камеру инертного газа.

Исследование элементного состава пленок проводилось методом рентгеноспектрального микроанализа с использованием энергодисперсионного спектро- 


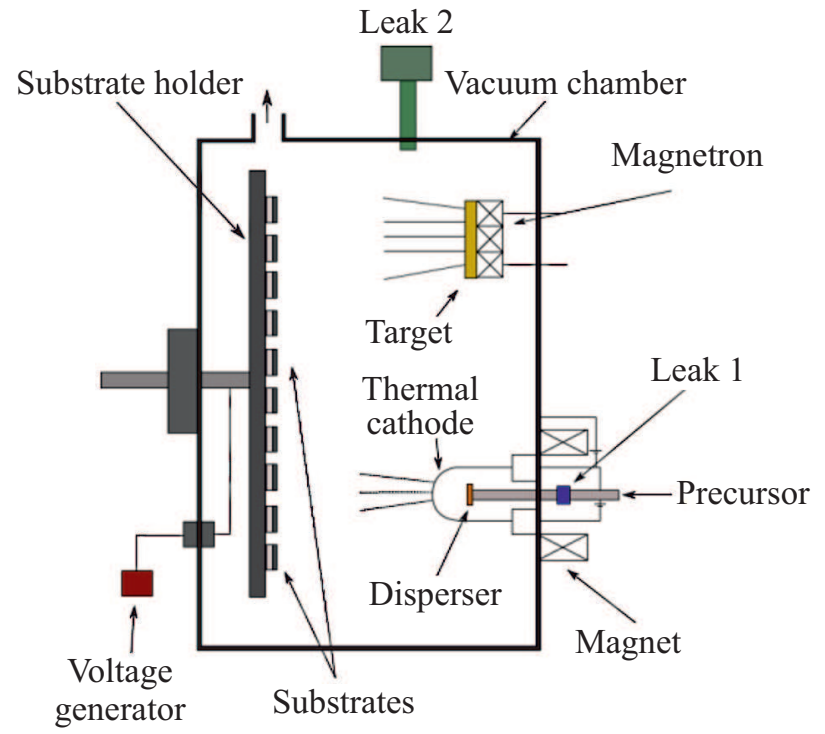

Рис. 1. Схема установки синтеза кремнийуглеродных пленок.

метра Inca x-Act. Для изучения морфологии поверхности пленок применялся атомно-силовой микроскоп NteGRA Prima. Частотные зависимости электропроводности и диэлектрических свойств при различных температурах, измерялись на установке для комплексного измерения диэлектрических свойств материалов Novocontrol Alpha-A. Исследования электрофизических свойств проводились на автоматизированной системе электрофизических измерений ASEC-03E. Механические свойства исследовались методом наноиндентирования пирамидой Берковича на нанотвердомере NHT2-TTX.

\section{3. Структурная модификация свойств}

Структурная модификация свойств аморфных кремнийуглеродных пленок осуществляется путем воздействия на материал различными внешними факторами в процессе их получения. Описанная выше установка позволяет осуществлять структурную модификацию пленки в процессе ее синтеза путем изменения:

- величины напряжения смещения на подложкодержателе;

- давления аргона в рабочей камере;

- типа, а следовательно, строения молекул кремнийорганического прекурсора;

- частоты переменного напряжения, создающего аксиальное поле.

Перечисленные факторы определяют строение частиц, образующих плазму, их кинетическую энергию при осаждении на подложку и оказывают влияние на структуру формируемой пленки.

Величина потенциала смещения на подложкодержателе определяет кинетическую энергию осаждающихся на подложке частиц в процессе роста пленки. Рост потенциала приводит к большей подвижности частиц на поверхности растущей пленки и увеличению вероятности формирования $s p^{3}$-связей на атомах углерода. В результате формируются более плотные пленки. Так при напряжении смещения на подложкодержателе $-200 \mathrm{~V}$ нанотвердость пленок составляет $22 \mathrm{GPa}$ и их модуль упругости $135 \mathrm{GPa}$, а при напряжении $-400 \mathrm{~V}$ указанные характеристики становятся равными 28 и $190 \mathrm{GPa}$ соответственно. Высота рельефа поверхности пленок уменьшается от 0.9 до $0.35 \mathrm{~nm}$ при изменении напряжения на подложкодержателе от -100 до $-1000 \mathrm{~V}$. Кроме того, как было отмечено в [8], одновременно происходит уменьшение удельной электропроводности материала примерно на порядок величины.

Присутствие ионов аргона в рабочей камере при наличии отрицательного смещения на подложкодержателе приводит к бомбардировке ими поверхности растущей пленки, интенсивность которой зависит от парциального давления аргона. В результате бомбардировки могут протекать два конкурирующих процесса: повышение эффективной температуры поверхности роста за счет передачи ей энергии ионов (что способствует формированию более упорядоченной структуры) и создание дополнительных дефектов при взаимодействии ионов с растущей пленкой (разупорядочение структуры). Проведенные эксперименты по влиянию парциального давления аргона в рабочей камере на кремнийуглеродные пленки показали [8], что увеличение парциального давления аргона ведет к росту плотности локализованных состояний в хвостах разрешенных зон. Поскольку для исследуемых материалов характерен прыжковый механизм проводимости [10], то указанный факт ведет к существенному росту электропроводности: от $3 \cdot 10^{-12} \Omega^{-1} \cdot \mathrm{cm}^{-1}$ при отсутствии в камере аргона, до $1 \cdot 10^{-6} \Omega^{-1} \cdot \mathrm{cm}^{-1}$ при давлении аргона $7 \cdot 10^{-4}$ Torr [8]. Таким образом, экспериментальные данные свидетельствуют, что при реализованных условиях эксперимента бомбардировка растущей пленки ионами аргона приводит к формированию более разупорядоченной структуры.

Структура и свойства кремнийуглеродных пленок зависят от структуры исходного кремнийорганического прекурсора. Для оценки этого влияния было проведено исследование пленок, изготовленных плазмохимическим разложением полифенилметилсилоксана (PPMS), химическая формула которого $\left(\mathrm{CH}_{3}\right)_{3} \mathrm{Si}\left[\mathrm{CH}_{3} \mathrm{C}_{6} \mathrm{H}_{5} \mathrm{SiO}\right]_{n} \mathrm{OSi}\left(\mathrm{CH}_{3}\right)_{3}$, и полиметилсилоксана (PMS), с химической формулой $\left(\mathrm{CH}_{3}\right)_{3} \mathrm{Si}\left[\left(\mathrm{CH}_{3}\right)_{2} \mathrm{SiO}\right]_{n} \mathrm{OSi}\left(\mathrm{CH}_{3}\right)_{3}$. Первый из них состоит из атомных цепочек с несимметричным строением, содержащих ответвления в виде фенильных колец и $\mathrm{CH}_{3}$-групп. В отличие от этого, PMS состоит из линейных молекул, содержащих симметрично расположенные $\mathrm{CH}_{3}$-группы. Химические составы прекурсоров достаточно близки друг к другу. PPMS отличается несколько большим содержанием углерода за счет наличия фенильных колец. Как показали результаты рентгеноспектрального микроанализа, химические составы пленок, 
Электропроводность кремнийуглеродных пленок

\begin{tabular}{c|c|c|c|c|c}
\hline Частота поля & $P_{\mathrm{Ar}}$, Torr & 0 & $3 \cdot 10^{-4}$ & $4.5 \cdot 10^{-4}$ & $7 \cdot 10^{-4}$ \\
\hline $1.76 \mathrm{MHz}$ & $\sigma, \Omega^{-1} \cdot \mathrm{cm}^{-1}$ & $3 \cdot 10^{-12}$ & $2 \cdot 10^{-9}$ & - & $1 \cdot 10^{-6}$ \\
$100 \mathrm{kHz}$ & $\sigma, \Omega^{-1} \cdot \mathrm{cm}^{-1}$ & $2 \cdot 10^{-10}$ & - & $3.5 \cdot 10^{-11}$ & -
\end{tabular}

полученных плазмохимическим разложением PPMS и PMS, близки к химическому составу соответствующих прекурсоров. Соотношение концентраций атомов углерода и кремния в пленках на основе PPMS составляет $3.9 \pm 0.4$, а в пленках на основе PMS $-2.7 \pm 0.3$.

Влияние технологических режимов на свойства пленок обоих типов имеет аналогичный характер. На рис. 2 представлены температурные зависимости электропроводности пленок, изготовленных при различных потенциалах смещения на подложкодержателе (рис. 2, $a$ ) и различном парциальном давлении аргона в рабочей камере (рис. $2, b)$. Как видно из рисунка, для обоих типов
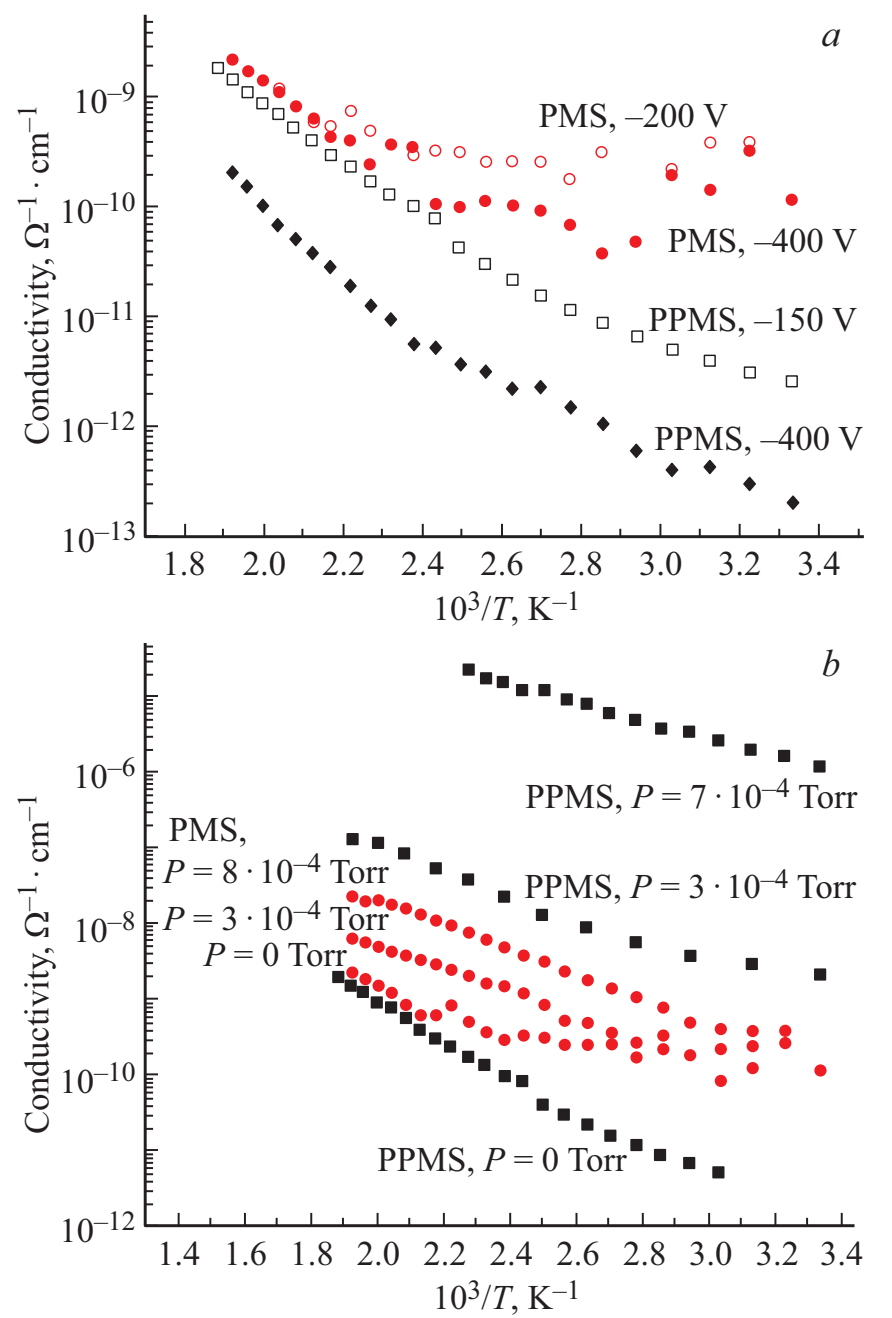

Рис. 2. Температурные зависимости электропроводности пленок на основе PPMS и PMS при различном смещении на подложкодержателе $(a)$ и различном парциальном давлении аргона при напряжении смещения $-200 \mathrm{~V}(b)$. пленок увеличение потенциала смещения на подложкодержателе приводит к уменьшению электропроводности пленок, а рост парциального давления аргона в рабочей камере вызывает увеличение их электропроводности. При этом, если изменения потенциала смещения подложкодержателя вызывают изменения абсолютных значений электропроводности в пределах одного порядка величины, то степень влияния давления аргона в рабочей камере на электропроводность пленок двух типов существенно выше. В случае пленок, полученных разложением полиметилсилоксана, изменение парциального давления аргона от 0 до $8 \cdot 10^{-3}$ Torr вызывали изменение электропроводности пленок на два порядка величины. А в пленках на основе полиметилфенилсилоксана при аналогичных изменениях парциального давления аргона изменения электропроводности достигали 6 порядков величины.

Данный факт, вероятно, может быть обусловлен более разнообразным составом частиц, возникающих в плазме при дефрагментации сложных молекул PPMS. Процесс осаждения этих частиц на поверхность роста в условиях бомбардировки ее ионами аргона приводит к росту концентрации дефектов и, соответственно, плотности локализованных состояний в хвостах разрешенных зон.

Описанные выше результаты были получены при использовании переменного напряжения частотой 1.76 MHz. Вместе с тем, как отмечалось выше, одной из возможностей структурной модификации является изменение частоты электрического поля. Следует отметить, что исследований влияния частоты электрического поля на свойства пленок, получаемых методами плазменного нанесения, проводилось весьма мало. Как правило, используются стандартные частоты мегагерцевого диапазона. В $[12,13]$ пленки $a-\mathrm{Si}: \mathrm{H}$ и $a-\mathrm{Si}_{1-x} \mathrm{Ge}_{x}: \mathrm{H}$ получали методом низкочастотного $(55 \mathrm{kHz})$ плазмохимического осаждения. Показано, что при этом на порядок увеличивается скорость роста пленок, по сравнению со стандартным методом высокочастотного осаждения, при сохранении невысокой плотности локализованных состояний и „высоких электронных свойств“.

В настоящей работе было проведено изготовление кремний-углеродных пленок на основе PPMS c использованием источника переменного напряжения частотой $100 \mathrm{kHz}$ при сохранении неизменными других параметров технологического режима. Результаты по электропроводности пленок, полученных высокочастотным $(1.76 \mathrm{MHz})$ и низкочастотным $(100 \mathrm{kHz})$ методами при различных давлениях аргона в рабочей камере приведены в таблице.

Как видно из таблицы, при отсутствии аргона в камере, электропроводность пленок, изготовленных при 


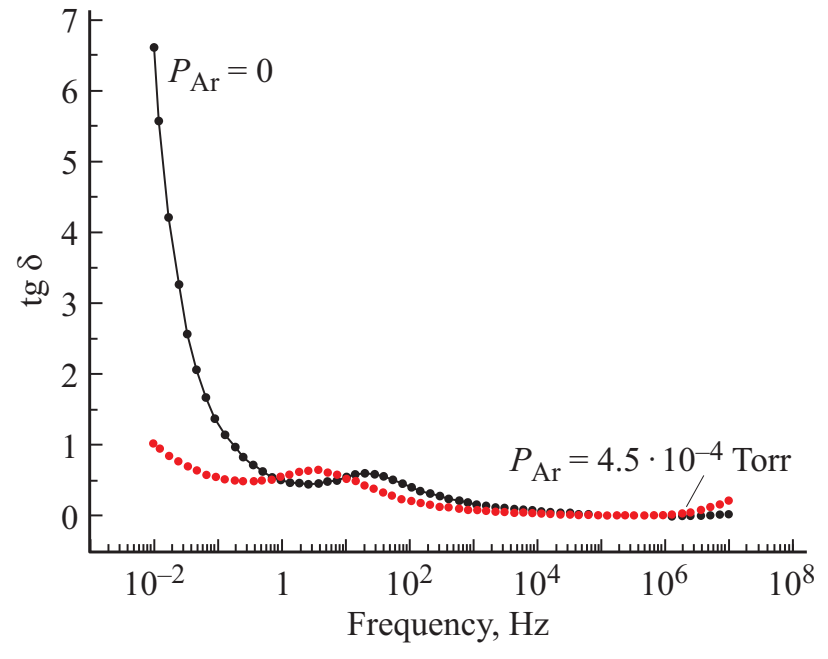

Рис. 3. Частотная зависимость тангенса диэлектрических потерь кремний-углеродных пленок на основе PPMS при низкочастотном методе изготовления.

низкой частоте электрического поля, на два порядка величины выше, чем пленок, полученных высокочастотным методом. Но главное отличие заключается в том, что введение аргона в рабочую камеру приводит к уменьшению электропроводности на порядок величины, в то время как в пленках, полученных при высокой частоте, при близких парциальных давлениях аргона, электропроводность увеличивается на три порядка величины. Кроме того следует отметить, что введение аргона в рабочую камеру при низкочастотном методе изготовления пленок, уменьшает значение тангенса угла диэлектрических потерь в низкочастотной области в несколько раз (рис. 3), что свидетельствует об уменьшении токов сквозной проводимости в этих образцах.

Изменение частоты аксиального электрического поля при получении пленок методом плазмохимического разложения кремнийорганических соединений ведет к существенным изменениям электронной и ионной подсистем плазмы, изменению величины отрицательного самосмещения подложкодержателя, что в свою очередь, изменяет интенсивность ионной бомбардировки растущей пленки и эффективную температуру поверхности роста.

В настоящее время на основании приведенных выше экспериментальных данных трудно сделать конкретные выводы о механизмах наблюдаемых изменений свойств. Однако очевидно, что изменение частоты электрического поля в процессе плазмохимического разложения является эффективным методом управления свойствами алмазоподобных кремнийуглеродных пленок.

\section{4. Химическая модификация свойств}

Благодаря высокой стабильности кремнийуглеродной структурной сетки, рассматриваемые материалы допускают введение большого количества примесей (до нескольких десятков атомных процентов переходных металлов [6]) без нарушения аморфного состояния матрицы. Это дает возможность в широких пределах управлять свойствами алмазоподобных кремнийуглеродных пленок методом химической модификации.

Введение в кремнийуглеродную матрицу металлов приводит, как правило, к образованию двухфазной системы - аморфная кремний-углеродная матрица с внедренными в нее нанокристаллами с размерами в единицы нанометров. При этом, последние представляют собой либо металл (при введении платины [14] или серебра [15]), либо карбид металла МеС (при введении переходных металлов [16]). На рис. 4 представлена зависимость удельной электропроводности танталсодержащей пленки от концентрации тантала. При введении тантала до 30 at.\% величина электропроводности возрастает на 9 порядков величины от $10^{-6}$ до $10^{3} \Omega^{-1} \cdot \mathrm{cm}^{-1}$. Как видно из рисунка, зависимость имеет три ярко выраженных участка. На первом участке, при малых концентрациях металла электропроводность плавно возрастает примерно на два порядка величины. На втором участке имеет место резкое возрастание электропроводности на 6 порядков величины. Наконец на третьем участке, когда концентрация металла превышает 22 at.\%, наблюдается слабая зависимость электропроводности от концентрации металла. Такой вид зависимостей типичен для перколяционных систем.

Результаты расчета концентрационной зависимости электропроводности танталсодержащей пленки в соответствии с используемым для таких систем приближением самосогласованного поля Бруггемана [17] показаны на рис. 4 пунктирной линией. При расчете электропроводность кремнийуглеродной матрицы принималась равной $1.2 \cdot 10^{-6} \Omega^{-1} \cdot \mathrm{cm}^{-1}$ (значение при нулевой концентрации металла на рисунке), электропроводность

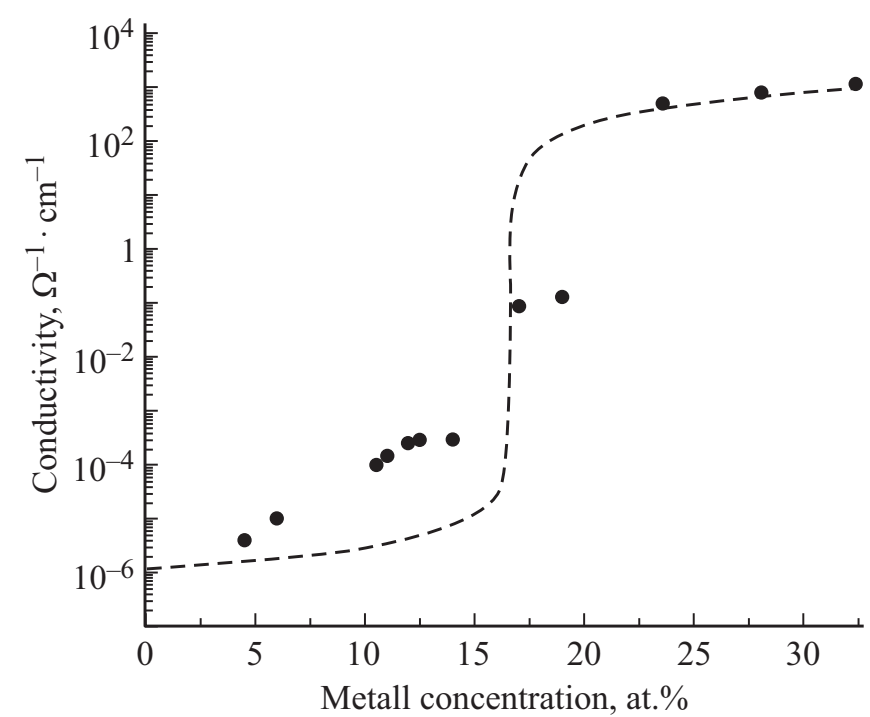

Рис. 4. Концентрационная зависимость электропроводности танталсодержащих пленок (точки - эксперимент, пунктирная кривая - расчет). 
карбида тантала $-2 \cdot 10^{3} \Omega^{-1} \cdot \mathrm{cm}^{-1}[18]$, концентрация проводящей фазы в соответствии с химической формулой ТаС принималась в два раза большей, чем концентрация металла. Из рисунка видно, что в области больших концентраций металла наблюдается хорошее соответствие экспериментальных и расчетных результатов. Удовлетворительное совпадение наблюдается также и на участке резкого изменения электропроводности. В то же время на первом участке экспериментальные точки лежат существенно выше расчетной кривой.

Наряду с электрофизическими свойствами происходит изменение механических свойств материала. Концентрационные зависимости нанотвердости пленок, содержащих вольфрам и молибден, представлены на рис. 5 [19].

Увеличение содержания металла в пленке приводит к росту концентрации нанокристаллов карбидов металлов [10]. Поскольку карбиды переходных металлов обладают высокими механическими характеристиками, то рост концентрации их нанокристаллов должен приводить к увеличению нанотвердости нанокомпозитного материала. Именно такая зависимость наблюдаются в случае вольфрамсодержащих образцов. Однако для молибденсодержащих пленок зависимость имеет другой характер. С ростом концентрации металла нанотвердость сначала уменьшается до минимального значения при 9at.\% молибдена, а затем возрастает, достигая величины для немодифицированного металлом образца при 15-16 at.\% молибдена. При концентрации металла 17-18 at.\% нанотвердость молибденсодержащей пленки начинает превышать значения для вольфрамсодержащего нанокомпозита.

\section{5. Структурно-химическая модификация свойств}

Как следует из приведенных данных, методы структурной и химической модификации позволяют в широких пределах управлять свойствами алмазоподобных кремнийуглеродных пленок. Однако ряд полученных экспериментальных результатов не удается объяснить в рамках моделей химической или структурной модификации. К ним относятся концентрационные зависимости электрофизических и механических свойств в области концентраций металла до 15-17 at.\%, описанные выше.

Вернемся к концентрационной зависимости электропроводности танталсодержащих пленок (рис. 4). Как указывалось выше, при невысоких значениях концентрации металла (до 15 at.\%) экспериментальные точки лежат выше расчетной кривой, причем с увеличением концентрации металла различие в их значениях возрастает от нуля до более чем порядка величины. Такое расхождение может быть в случае, если образование нанокристаллов карбида металла не только уменьшает долю диэлектрической фазы кремний углеродной матрицы, но и изменяет ее электропроводность. Для понимания причин изменения свойств кремнийуглеродной матрицы при введении в материал переходных металлов необходимо

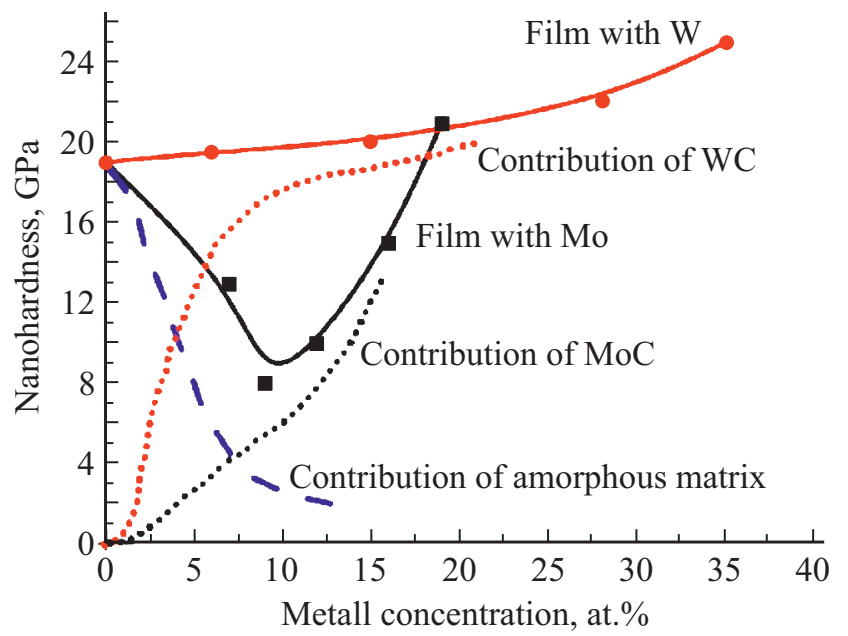

Рис. 5. Концентрационные зависимости нанотвердости молибден- и вольфрамсодержащих кремнийуглеродных пленок (штриховая кривая - иллюстрация вклада аморфной матрицы, а пунктирные кривые - нанокристаллической фазы в нанотвердость материала).

принять во внимание, что при образовании карбидов металла, углерод заимствуется из кремнийуглеродной матрицы, что приводит к изменению структуры и свойств последней. Изъятие атомов углерода ведет к росту концентрации оборванных связей и к увеличению плотности локализованных состояний в хвостах разрешенных зон. В свою очередь, это приводит к увеличению прыжковой проводимости в диэлектрической матрице. Таким образом, при химической модификации алмазоподобных кремнийуглеродных пленок переходными металлами, кроме образования новой фазы (нанокристаллы карбида металла), происходит модификация структуры исходной кремнийуглеродной матрицы вследствие изъятия из нее атомов углерода при неизменном суммарном содержании углерода в материале.

В случае концентрационных зависимостей механических свойств (рис. 5) ситуация оказывается сложнее. Перераспределение углерода между нанокристаллической карбидной фазой и аморфной кремнийуглеродной матрицей приводит к появлению двух конкурирующих процессов: с одной стороны рост объема карбидной фазы увеличивает ее вклад в механические свойства нанокомпозита, а с другой стороны, обеднение аморфной матрицы углеродом вызывает снижение ее вклада. Эти процессы могут вызывать появление экстремума на концентрационных зависимостях механических свойств, что и наблюдается на концентрационной зависимости нанотвердости молибденсодержащих пленок. Однако, как видно из рис. 5, минимум на концентрационной зависимости нанотвердости отсутствует в пленках с вольфрамом.

Для объяснения этого факта необходимо принять во внимание, что размеры нанокристаллов карбидов молибдена и вольфрама существенно различаются даже при близких концентрациях металла в кремний-углеродных 
пленках (средние размеры нанокристаллов МоС составляют $2.5 \mathrm{~nm}$, а нанокристаллов $\mathrm{WC}$ - около $1 \mathrm{~nm}$ ) [19]. Так как при неизменном количестве металла концентрация нанокристаллов обратно пропорциональна их объему, а расстояние между ними пропорционально размеру частиц, то количество нанокристаллов карбида вольфрама в вольфрамсодержащих пленках будет больше, а расстояния между ними меньше, чем в пленках с нанокристаллами карбида молибдена. Учитывая одинаковую химическую формулу карбидов вольфрама и молибдена и близкие объемы их элементарных ячеек (WC $\left.62.3 \AA^{3}, \mathrm{MoC}-60.5 \AA^{3}\right)$, была проведена оценка количества нанокристаллов карбида, попадающих в объем идентируемой области при исследовании механических свойств индентором Бертковича [19]. При концентрации металла 10 at.\% количество нанокристаллов карбида вольфрама в идентируемой области лежит в пределах $(1.1-1.7) \cdot 10^{6}$, а количество нанокристаллов карбида молибдена $-(0.4-1.4) \cdot 10^{5}$. Таким образом, количество нанокристаллов, находящихся в области идентирования, в случае вольфрамсодержащего нанокомпозита на порядок величины выше, чем в пленках молибденсодержащего нанокомпозита. Это приводит к различной степени влияния карбидной фазы на механические свойства материала при одинаковом ее содержании в вольфрами молибденсодержащих пленках.

На рис. 5 штриховыми и пунктирными линиями проиллюстрированы вклады аморфной кремнийуглеродной матрицы и нанокристаллической карбидной фазы в величину нанотвердости материала при различных концентрациях металла. Как видно из рисунка, в случае вольфрамсодержащих пленок, вклад карбидной фазы в величину нанотвердости с увеличением концентрации металла нарастает существенно быстрее, чем в молибденсодержащих пленках, благодаря чему минимум на экспериментальной зависимости не наблюдается.

\section{6. Заключение}

Структурная и химическая модификации аморфных алмазоподобных кремнийуглеродных пленок являются эффективным методом управления электрофизическими и механическими свойствами этих материалов. Так совместное использование указанных двух методов позволяет изменять электропроводность более чем на 16 порядков величины. Вместе с тем, для предсказуемого изменения свойств при использовании химической модификации необходимо учитывать влияние вводимых примесей на структуру кремнийуглеродной матрицы. Учет этого влияния (структурно-химической модификации) позволяет количественно описать зависимости свойств пленок от концентрации вводимого металла.

\section{Финансирование работы}

Работа выполнена при финансовой поддержке Российского фонда фундаментальных исследований (грант № 19-07-00021).

\section{Конфликт интересов}

Авторы заявляют, что у них нет конфликта интересов.

\section{Список литературы}

[1] Н.А. Горюнова, Б.Т. Коломиец. Изв. АН ССС. Сер. физ. 20, 1496 (1956).

[2] W.E. Spear, P.G. Le Comber. Solid State Commun. 17, 1193 (1975).

[3] S.R. Ovshinsky. In: Amorphous and Liquid Semiconductors / Ed. W.E. Spear. University of Edinburgh, UK (1977) P. 519.

[4] A. Popov, N. Mikhalev, V. Shemetova. Phil. Mag. B 47, 73 (1983).

[5] А.И. Попов, В.А. Воронцов, И.А. Попов. ФТП 35, 665 (2001).

[6] Š. Meškinis, A. Tamulevičiené. Mater. Sci. (Medžiagotyra) 17, 358 (2011).

[7] F. Mangolini, B.A. Krick, T.D.B. Jacobs, S.R. Khanal, F. Streller, J.B. McClimon, J. Hilbert, S.V. Prasad, T.W. Scharf, J.A. Ohlhausen, J.R. Lukes, W.G. Sawyer, R.W. Carpick. Carbon 130, 127 (2018).

[8] A.I. Popov, A.D. Barinov, M.Y. Presniakov. J. Nanoelectron. Optoelectron. 9, 787 (2014).

[9] E.V. Zavedeev, O.S. Zilova, M.L. Shupegin, A.D. Barinov, N.R. Arutyunyan, T. Roch, S.M. Pimenov. Appl. Phys. A 122:961. DOI: 10.1007/s00339-016-0508-7(2016).

[10] A. Popov. Disordered Semiconductors: Physics and Applications. 2d ed. Pan Stanford Publ. (2018). 327 p.

[11] М.Л. Шупегин. Завод. лаб. Диагностика материалов 79, 28 (2013).

[12] Б.Г. Будагян, А.А. Шерченков, А.Е. Бердников, В.Д. Черномордик. Микроэлектроника 29, 442 (2000).

[13] А.А. Шерченков. Материалы электронной техники 1, 48 (2003).

[14] М.Д. Малинкович, Ю.Н. Пархоменко, Д.С. Поляков, М.Л. Шупегин. Материалы электронной техники 1, 41 (2010).

[15] T. Tamulevičius, D.Tamulevičiené, A. Virganavičius, V. Vasiliauskas, Š. Kopustinskas, S. Meškinis. Nucl. Instrum. Meth. Phys. Res. B 341, 1 (2014).

[16] М.Ю. Пресняков, А.И. Попов, Д.С. Усольцева, М.Л. Шупегин, А.Л. Васильев. Рос. нанотехнологии 9, 59 (2014).

[17] А.А. Снарский, И.В. Безсуднов, В.А. Севрюков. Процессы переноса в макроскопически неупорядоченных средах: от теории среднего поля до перколяции. ЛКИ, М. (2007). $304 \mathrm{c}$.

[18] Я.М. Колотырин, В.М. Княжева. В сб.: Итоги науки и техники. ВИНИТИ, М. (1974). Т. 3. С. 5.

[19] А.Д. Баринов, А.И. Попов, М.Ю. Пресняков. Неорган. материалы, 53, 706 (2017).

Редактор Т.Н. Василевская 